\title{
A multicenter phase II study of bendamustine, rituximab, and cytarabine (BRAC) for relapsed or refractory patients with follicular lymphoma or mantle cell lymphoma
}

\author{
Nobuhiko Nakamura1*®D, Senji Kasahara², Junichi Kitagawa², Hiroshi Nakamura', Michio Sawada ${ }^{3}$, \\ Kenji Fukuno ${ }^{4}$, Yuhei Shibata ${ }^{2}$, Yuto Kaneda ${ }^{4}$, Takeshi Hara' ${ }^{5}$, Nobuhiro Kanemura ${ }^{1}$, Hisashi Tsurumi ${ }^{1,5}$ and \\ Masahito Shimizu ${ }^{1}$
}

\begin{abstract}
This phase II clinical trial aimed to evaluate the efficacy and safety of the combination therapy of bendamustine, cytarabine, and rituximab (BRAC) in patients with relapsed or refractory follicular lymphoma (FL) or mantle cell lymphoma $(\mathrm{MCL})$. Thirteen patients were enrolled and received a median of 4 cycles (range 2-6) of BRAC. The complete response rate was $61.5 \%$, and the overall response rate was $84.6 \%$; the 2 -year overall survival was $76.9 \%$, and the 2 -year progression-free survival was $69.2 \%$. Although all patients received G-CSF prophylaxis, grade 3 or higher neutropenia was observed in all cycles, and the incidence of febrile neutropenia was 20\%. Grade 4 thrombocytopenia was observed in $92.5 \%$ of all cycles, and platelet transfusion was performed in 94\%. Although hematological toxicity was relatively high, BRAC therapy was effective for relapsed and refractory FL or MCL. Further studies are needed to determine the optimal dose of BRAC therapy.

Trial registration The UMIN Clinical Trials Registry, UMIN000009797. Registered 17 January 2013, https://upload.umin.ac. jp/cgi-open-bin/ctr/ctr_view.cgi?recptno=R000011103
\end{abstract}

Keywords: Follicular lymphoma, Mantle cell lymphoma, Bendamustine, Rituximab, Cytarabine

\section{To the Editor}

The combination of rituximab and chemotherapy has significantly improved outcomes for B-cell non-Hodgkin lymphoma (NHL) patients. However, conventional therapies cannot cure follicular lymphoma (FL) and mantle cell lymphoma (MCL) [1, 2]. Bendamustine has demonstrated high efficacy as monotherapy and in combination

\footnotetext{
*Correspondence: nnaka@gifu-u.ac.jp

1 Department of Hematology and Infectious Disease, Gifu University Hospital, 1-1, Yanagido, Gifu 501-1194, Japan

Full list of author information is available at the end of the article
}

with rituximab for relapsed or refractory indolent B-cell NHL and MCL [3]. Cytarabine has been reported to be synergistic with bendamustine and is a new candidate for combination therapy [4]. Results of three-drug combination therapy of bendamustine, cytarabine, and rituximab (BRAC) in patients with MCL patients conducted overseas have shown high efficacy and safety $[5,6]$. Although no validated phase III comparative study has yet been conducted, bendamustine and cytarabine combination therapy may be a promising treatment regimen. Therefore, we conducted a phase II clinical trial to evaluate

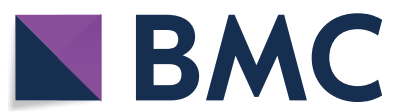

(c) The Author(s) 2022. Open Access This article is licensed under a Creative Commons Attribution 4.0 International License, which permits use, sharing, adaptation, distribution and reproduction in any medium or format, as long as you give appropriate credit to the original author(s) and the source, provide a link to the Creative Commons licence, and indicate if changes were made. The images or other third party material in this article are included in the article's Creative Commons licence, unless indicated otherwise in a credit line to the material. If material is not included in the article's Creative Commons licence and your intended use is not permitted by statutory regulation or exceeds the permitted use, you will need to obtain permission directly from the copyright holder. To view a copy of this licence, visit http://creativecommons.org/licenses/by/4.0/. The Creative Commons Public Domain Dedication waiver (http://creativecommons.org/publicdomain/zero/1.0/) applies to the data made available in this article, unless otherwise stated in a credit line to the data. 
efficacy and safety of BRAC. Due to slow accrual, the study was prematurely closed with a total of only 13 patients.

A multicenter, open-label, single-arm, phase II clinical trial was conducted in 3 hospitals from the Gifu Hematology Study Group in Japan. Patients were eligible if they were aged 20-80 years, Eastern Cooperative Oncology Group performance status of $0-2$ and had histologically confirmed, relapsed or refractory FL or MCL according to the WHO classification [7]. Patients with histological transformation to a higher degree of lymphoma have been ruled out before the initiation of BRAC treatment. All patients received BRAC (rituximab $375 \mathrm{mg} / \mathrm{m}^{2}$ on day 1 ; bendamustine $90 \mathrm{mg} / \mathrm{m}^{2}$ over 30-60 min on days 2 and 3; cytarabine $600 \mathrm{mg} /$ $\mathrm{m}^{2}$ over a $2-\mathrm{h}$ infusion on days 2-4; all administered intravenously) every 4 weeks for up to 6 cycles. Prophylaxis with G-CSF (filgrastim $50 \mu \mathrm{g} / \mathrm{m}^{2}$ ) was given $24 \mathrm{~h}$ after the last cytarabine dose in every cycle. If grade 3 or higher non-hematologic toxicity was observed, the dose of bendamustine was reduced from $90 \mathrm{mg} / \mathrm{m}^{2}$ to $60 \mathrm{mg} / \mathrm{m}^{2}$ in the subsequent cycles. The dose of rituximab and cytarabine was not reduced. The primary endpoint was the complete response (CR) rate. The response was evaluated according to the Cheson criteria, 2007 [8]. The CR rate for BR therapy in patients with relapsed or refractory indolent B-cell NHL and MCL is $54-59 \%$ [9]. In addition, the CR rate for BRAC therapy in relapsed MCL is $70 \%$ [5]. Therefore, we set the expected $\mathrm{CR}$ rate at $70 \%$ and the threshold $\mathrm{CR}$ rate at $45 \%$, one-sided $\alpha$ error of 0.05 , and $\beta$ error of 0.2 , and the minimum number of patients required at 24 . We assumed that $10 \%$ of the enrolled patients would be ineligible, and the sample size was set at 27 .

Though enrollment of 27 patients was planned, 13 patients were enrolled from May 2013 to May 2018. The demographics and characteristics of patients are shown in Table 1. The median age was 65 (53-73) years, and 6 patients $(46.2 \%)$ were male. The histological types were FL in 9 patients and MCL in 4 patients. The median number of previous treatment regimens was 1 (range: 1-6), and 3 patients (23.1\%) were refractory to their last chemotherapy. All patients had received rituximab-containing chemotherapy, four patients had been treated with bendamustine, two patients had been treated with cytarabine, and none had been treated with Bruton's tyrosine kinase (BTK) inhibitor. Patients received a median of 4 cycles (range 2-6) of BRAC. Seven of 13 patients (53.8\%) were able to complete the scheduled treatment. One patient received an autologous hematopoietic stem-cell transplantation (HSCT) after 4 cycles, one patient received an allogeneic HSCT after 3 cycles, and no patient received BTK inhibitor maintenance. The CR rate was $61.5 \%$ [95\% confidence interval (CI) 31.6-86.1], and the overall response (OR) rate was $84.6 \%(95 \% \mathrm{CI}$ 54.6-86.1). In 9 patients with FL, the CR rate was $66.7 \%$, and the OR rate was $100 \%$. The median follow-up for 10 survivors from enrolment was 31.2 months (range 20.839.6 months). The 2-year overall survival (OS) was $76.9 \%$ (95\% CI 44.2-91.9\%) [Additional file 1: Figure S1(A)],

Table 1 Patients demographics and characteristics

\begin{tabular}{|c|c|c|c|c|c|c|}
\hline Patient & Age, gender & Diagnosis & Previous regimen & $\begin{array}{l}\text { Cycles of } \\
\text { BRAC }\end{array}$ & Response & Treatment after BRAC \\
\hline 1 & $61, F$ & FL G1 & $\mathrm{R}-\mathrm{CHOP}$ & 5 & PR & - \\
\hline 2 & $53, F$ & FL G3b & $\mathrm{R}-\mathrm{CHOP}$ & 4 & $C R$ & auto HSCT \\
\hline 3 & $71, F$ & FL G2 & R-THP-COP, R-IMVP-16/CBDCA, R-B, CHASER & 4 & $C R$ & - \\
\hline 4 & $66, M$ & FL G1 & R-THP-COP & 6 & PR & - \\
\hline 5 & $63, F$ & $\mathrm{FL} \mathrm{G2}$ & $\mathrm{R}-\mathrm{CHOP}$ & 4 & $C R$ & - \\
\hline 6 & $61, M$ & $\mathrm{MCL}$ & R-HyperCVAD/MA & 3 & $C R$ & - \\
\hline 7 & $67, M$ & $\mathrm{MCL}$ & R-CHOP, R-IMVP-16/CBDCA, CHASER, R-HyperCVAD/MA & 2 & NA & - \\
\hline 8 & $57, M$ & FL G2 & $\mathrm{R}-\mathrm{CHOP}, \mathrm{R}-\mathrm{B}$ & 3 & PR & allo HSCT \\
\hline 9 & $69, F$ & FL G2 & R-THP-COP, R-B, R, R-Flu, GCD-R, Ibritumomab Tiuxetan & 3 & $C R$ & - \\
\hline 10 & $72, \mathrm{M}$ & $\mathrm{MCL}$ & $\mathrm{R}-\mathrm{CHOP}, \mathrm{R}-\mathrm{B}$ & 2 & NA & - \\
\hline 11 & $72, \mathrm{M}$ & FL G2 & $\mathrm{R}-\mathrm{CHOP}, \mathrm{R}-\mathrm{B}$ & 4 & $C R$ & - \\
\hline 12 & $65, F$ & FL G1 & $\mathrm{R}-\mathrm{CHOP}$ & 4 & $C R$ & - \\
\hline 13 & $69, \mathrm{~F}$ & $\mathrm{MCL}$ & $\mathrm{R}-\mathrm{CHOP}$ & 6 & $C R$ & - \\
\hline
\end{tabular}

FL: follicular lymphoma; G: grade; MCL: mantle cell lymphoma; R-CHOP: rituximab, cyclophosphamide, doxorubicin, vincristine, and prednisolone; R-THP-COP: rituximab, cyclophosphamide, pirarubicine, vincristine, and prednisolone; R-IMVP-16/CBDCA: rituximab, ifosfamide, methotrexate, etoposide, carboplatin, and methylprednisolone; R-B: rituximab, bendamustine; CHASER: cyclophosphamide, high dose cytarabine, dexamethasone, etoposide, and rituximab; R-HyperCVAD/MA: rituximab, hyperfractionated cyclophosphamide, vincristine, doxorubicin, and dexamethasone, alternating with high dose methotrexate and cytarabine; $R$ : rituximab; R-Flu: rituximab, fludarabine; GCD-R: gemcitabine, carboplatin, dexamethasone, and rituximab; PR: partial response; CR: complete response; NA: not applicable; HSCT: hematopoietic stem cell transplantation 
and the 2-year progression-free survival (PFS) was $69.2 \%$ (95\% CI 37.3-87.2\%) [Additional file 1: Figure S1(B)].

Fifty cycles of BRAC were given. Table 2 summarizes the hematological and non-hematological toxicities. Although all patients received G-CSF prophylaxis, grade 3 or higher neutropenia was observed in all cycles, and the incidence of febrile neutropenia was $20 \%$. Grade 4 thrombocytopenia was observed in $92.5 \%$ of all cycles, and platelet transfusion was performed in 47 of 50 cycles (94\%). Treatment initiation was delayed in 7 of 13 patients (53.8\%), primarily due to treatment toxicity. The dose of bendamustine was reduced in 6 of 50 patient cycles $(12.0 \%)$.

In the present study, the efficacy and safety of BRAC therapy for relapsed or refractory FL or MCL were evaluated. A good response rate (CR rate: $61.5 \%$, OR rate: $84.6 \%$ ) was seen. In particular, this is the first study to confirm the response to BRAC therapy of relapsed or refractory FL (CR rate: $66.7 \%$, OR rate: $100 \%)$. On the other hand, hematological toxicity was relatively high, with $20 \%$ (10/50 cycles) having febrile neutropenia and the need for platelet transfusion in almost all cycles. Visco et al. reported the use of R-BAC (rituximab $375 \mathrm{mg} / \mathrm{m}^{2}$, bendamustine $70 \mathrm{mg} / \mathrm{m}^{2}$, cytarabine $800 \mathrm{mg} / \mathrm{m}^{2}$ ) in elderly patients with previously untreated or relapsed or refractory MCL [5], and they reduced the dose of cytarabine to $500 \mathrm{mg} / \mathrm{m}^{2}$ in the next study because of high hematological toxicity [6]. Unfortunately, sufficient conclusions could not be drawn because the present study closed prematurely due to slow accrual, but it was possible to show that BRAC therapy might be useful, especially for FL. The reason for the slow accrual is uncertain, but one reason may have been the emergence of new drugs. For example, obinutuzumab and lenalidomide were approved for

Table 2 Treatment cycles with hematological toxicities and nonhematological toxicities (50 patient-cycles)

\begin{tabular}{lcc}
\hline Toxicity, $\mathbf{n}(\%)$ & Grade $\mathbf{3}$ & Grade 4 \\
\hline Hematologic & & \\
$\quad$ Neutropenia & $5(10.0)$ & $41(82.0)$ \\
Anemia & $39(78.0)$ & $1(2.0)$ \\
Thrombocytopenia & $4(8.0)$ & $46(92.0)$ \\
Non-hematologic & & \\
Sepsis* & $0(0.0)$ & $1(2.0)$ \\
Febrile neutropenia & $10(20.0)$ & $0(0.0)$ \\
Cytomegalovirus infection & $2(4.0)$ & $0(0.0)$ \\
Hypokalemia & $1(2.0)$ & $0(0.0)$ \\
Hemothorax & $0(0.0)$ & $1(2.0)$ \\
Hyperamylasemia & $2(4.0)$ & $0(0.0)$ \\
\hline
\end{tabular}

*The causative organism of sepsis was Bacillus spp the treatment of FL, and bortezomib and ibrutinib were approved for the treatment of MCL in Japan during the study period which may have increased the number of treatment options and slowed patient enrollment. BTK inhibitors, such as ibrutinib, have been reported to be synergistic with rituximab [10] and are effective agents against MCL. Furthermore, the usefulness of antiCD19 chimeric antigen receptor (CAR) T-cell therapy for $\mathrm{FL}$ and MCL has been recently reported $[11,12]$. Although administration of BRAC before leukocyte apheresis should be avoided because bendamustine reduces the efficiency of lymphocyte collection, BRAC may be effective as bridging chemotherapy to CAR-T. Further studies are needed to determine the optimal dose and timing of BRAC therapy.

\section{Abbreviations}

NHL: Non-Hodgkin lymphoma; FL: Follicular lymphoma; MCL: Mantle cell lymphoma; CR: Complete response; PR: Partial response; OR: Overall response; OS: Overall survival; PFS: Progression-free survival; Cl: Confidence interval; BTK: Bruton's tyrosine kinase; CAR: Chimeric antigen receptor.

\section{Supplementary Information}

The online version contains supplementary material available at https://doi. org/10.1186/s40164-022-00264-3.

Additional file 1: Figure. S1 Overall survival (A) and progression-free survival (B) for all patients $(n=13)$. Overall survival (C) and progression-free survival (D) for follicular lymphoma (FL) $(n=9)$ and mantle cell lymphoma $(n=4)$.

\section{Acknowledgements}

The authors are grateful to the members of the Gifu Hematology Study Group for their support of this study.

\section{Authors' contributions}

NN collected, analyzed, and interpreted the data and wrote the manuscript; SK, JK, MS, KF, TH, NK and HT conceived and designed the study; NN, SK, JK, $\mathrm{HN}, \mathrm{MS}, \mathrm{KF}, \mathrm{YS}$ and YK recruited patients; All authors read and approved the final manuscript.

Funding

None.

\section{Availability of data and materials}

The datasets used and/or analysed during the current study are available from the corresponding author on reasonable request.

\section{Declarations}

Ethics approval and consent to participate

Ethics approval was granted by the institutional review board at each participating institution. All patients provided written informed consent.

\section{Consent for publication}

Not applicable.

\section{Competing interests}

The authors declare that they have no competing interests. 


\section{Author details}

'Department of Hematology and Infectious Disease, Gifu University Hospital, 1-1, Yanagido, Gifu 501-1194, Japan. ${ }^{2}$ Department of Hematology, Gifu Municipal Hospital, Gifu, Japan. ${ }^{3}$ Department of Hematology, Gifu Red Cross Hospital, Gifu, Japan. ${ }^{4}$ Department of Hematology, Takayama Red Cross Hospital, Gifu, Japan. ${ }^{5}$ Department of Hematology, Matsunami General Hospital, Gifu, Japan.

Received: 26 October 2021 Accepted: 16 February 2022

Published online: 25 February 2022

\section{References}

1. Hanel W, Epperla N. Evolving therapeutic landscape in follicular lymphoma: a look at emerging and investigational therapies. J Hematol Oncol. 2021;14:104

2. Ladha A, Zhao J, Epner EM, Pu JJ. Mantle cell lymphoma and its management: where are we now? Exp Hematol Oncol. 2019;8:2.

3. Rummel M, Kaiser $U$, Balser $C$, et al. Bendamustine plus rituximab versus fludarabine plus rituximab for patients with relapsed indolent and mantle-cell lymphomas: a multicentre, randomised, open-label, noninferiority phase 3 trial. Lancet Oncol. 2016;17:57-66.

4. Castegnaro S, Visco C, Chieregato K, et al. Cytosine arabinoside potentiates the apoptotic effect of bendamustine on several B- and T-cell leukemia/lymphoma cells and cell lines. Leuk Lymphoma. 2012;53:2262-8.

5. Visco C, Finotto S, Zambello R, et al. Combination of rituximab, bendamustine, and cytarabine for patients with mantle-cell non-Hodgkin lymphoma ineligible for intensive regimens or autologous transplantation. J Clin Oncol. 2013:31:1442-9.

6. Visco C, Chiappella A, Nassi L, et al. Rituximab, bendamustine, and lowdose cytarabine as induction therapy in elderly patients with mantle cell lymphoma: a multicentre, phase 2 trial from Fondazione Italiana Linfomi. Lancet Haematol. 2017:4:e15-23.

7. Swerdlow SH, Campo E, Pileri SA, et al. The 2016 revision of the World Health Organization classification of lymphoid neoplasms. Blood. 2016;127:2375-90.

8. Cheson BD, Pfistner B, Juweid ME, et al. Revised response criteria for malignant lymphoma. J Clin Oncol. 2007;25:579-86.

9. Robinson $\mathrm{KS}$, Williams $\mathrm{ME}$, van der Jagt $\mathrm{RH}$, et al. Phase II multicenter study of bendamustine plus rituximab in patients with relapsed indolent B-cell and mantle cell non-Hodgkin's lymphoma. J Clin Oncol. 2008:26:4473-9.

10. Albertsson-Lindblad A, Freiburghaus C, Jerkeman M, Ek S. Ibrutinib inhibits antibody dependent cellular cytotoxicity induced by rituximab or obinutuzumab in MCL cell lines, not overcome by addition of lenalidomide. Exp Hematol Oncol. 2019:8:16

11. Hirayama AV, Gauthier J, Hay KA, et al. High rate of durable complete remission in follicular lymphoma after CD19 CAR-T cell immunotherapy. Blood. 2019;134:636-40.

12. Wang M, Munoz J, Goy A, et al. KTE-X19 CAR T-cell therapy in relapsed or refractory mantle-cell lymphoma. N Engl J Med. 2020;382:1331-42.

\section{Publisher's Note}

Springer Nature remains neutral with regard to jurisdictional claims in pub lished maps and institutional affiliations.

Ready to submit your research? Choose BMC and benefit from:

- fast, convenient online submission

- thorough peer review by experienced researchers in your field

- rapid publication on acceptance

- support for research data, including large and complex data types

- gold Open Access which fosters wider collaboration and increased citations

- maximum visibility for your research: over $100 \mathrm{M}$ website views per year

At $\mathrm{BMC}$, research is always in progress.

Learn more biomedcentral.com/submissions 